\title{
Analisis Migrasi Tenaga Kerja Indonesia di Taiwan Menggunakan Cost Benefit Analysis (Studi Kasus di Kabupaten Malang)
}

\author{
Muhammad Tody Arsyianto', Mohammad Rizal² \\ ${ }^{1}$ Fakultas Ekonomi \& Bisnis Universitas Islam Malang \\ Email :TodyArsiyanto@yahoo.com \\ ${ }^{2}$ Fakultas Ekonomi \& Bisnis Universitas Islam Malang \\ Email :mrizal187@gmail.com
}

\begin{abstract}
Abstrak
Pada dasarnya Tenaga Kerja Indonesia (TKI) yang bekerja di luar negeri dilatarbelakangi oleh tekanan ekonomi, maka pemikiran para TKI berpusat pada remitansi yang besar, dengan stigma tersebut ada rasionalitas calon TKI memilih negara tujuan tempat bekerja yang memiliki standar upah tinggi, dengan biaya keberangkatan yang serendah mungkin. Bagi Pemerintah, TKI yang bekerja di luar negeri memberikan sumbangan devisa negara yang tidak kecil. Taiwan menjadi salah satu tujuan utama untuk bekerja dikarenakan pada Negara Taiwan ini mempunyai standar gaji yang lebih tinggi dibanding Hongkong dan Singapura. Hasil penelitian menunjukkan bahwa: (1) Ditemukan bahwa untuk pra penempatan beberapa PJTKI ada yang memberikan dana tambahan untuk calon TKI namun ada yang meminta untuk membayar biaya pemberangkatan dan potong gaji, ketika berada di Taiwan kontrak kerja mudah diperpanjang dan standar upah tinggi tetapi sikap majikan tempramen dan kendala bahasa sedangkan setelah kembali ke Indonesia purna TKI mendapatkan modal yang tinggi dikarenakan standar upah yang tinggi namun hal itu menyebabkan purna TKI lebih konsumtif (2) Berdasarkan hasil perhitungan Cost Benefit Analysis dari 15 mantan TKI secara keseluruhan memenuhi syarat untuk diprioritaskan, karena dalam metode Net Present Benefit (NPB) maupun dengan Metode Benefit Cost Ratio (BCR) semuanya menunjukan bahwa hasil perhitungan yang layak untuk dijalankan.
\end{abstract}

Kata Kunci: Migrasi, Tenaga Kerja Indonesia, Cost Benefit Analysis

\begin{abstract}
Basically Indonesian Labors (TKI) who work abroad are motivated by economic pressure, so the thinking of Indonesian migrant labors is centered on great remittances, with this stigma there is rationality of prospective migrant labors choosing the destination country of work that has high wage standards, with as low as possible. For the Government, migrant labors who work abroad contribute to the country's foreign exchange which is not small. Taiwan is one of the main destinations for work because in Taiwan the country has a higher standard of salary than Hong Kong and Singapore. The results showed that: (1) It was found that for pre-placement some PJTKls provided additional funds for prospective migrant labors, but there were those who asked to pay the costs of departure and deduction of wages, while in Taiwan work contracts were easily extended and high wage standards but employer attitudes temperament and language barrier, while after returning to Indonesia, the former TKI gets high capital due to high wage standards, but it causes the former TKI to be more consumptive (2) Based on the calculation of Cost Benefit Analysis of 15 ex-migrants as a whole qualifies for priority, because in the Net Present Benefit (NPB) and the Method of Benefit Cost Ratio (BCR) all imply that the results of calculations feasible.
\end{abstract}

Keywords: Migration, Labor Migration, Cost Benefit Analysis 


\section{PENDAHULUAN}

Ada banyak faktor yang mempengaruhi keputusan Tenaga Kerja Indonesia (TKI) untuk bermigrasi mencari pekerjaan diluar negeri serta memilih negara tertentu sebagai tujuannya. Sampai saat ini, pengiriman TKI untuk bekerja di luar negeri masih didominasi oleh tenaga berpendidikan dan berkeahlian rendah (low education and skill). Berdasarkan jabatan pekerjaannya, sebagian besar juga bekerja sebagai pekerja rumah tangga dan pengasuh anak/pengurus orang tua (caregiver/caretaker). Pada dasarnya TKI yang bekerja di luar negeri dilatarbelakangi oleh tekanan ekonomi, maka pemikiran para TKI berpusat pada remitansi yang besar, dengan stigma tersebut ada rasionalitas calon TKI memilih negara tujuan tempat bekerja yang memiliki standar upah tinggi, dengan biaya keberangkatan yang serendah mungkin. Alasan utama untuk memilih bekerja di luar negeri juga didominasi oleh alasan ekonomi, baik sebagai faktor pendorong di daerah asal maupun faktor penarik di negara tujuan (Aswatini, 2002; UN-ESCAP \& UN-ESCWA, 2013). Bagi Pemerintah sendiri TKI yang bekerja di luar negeri memberikan sumbangan devisa negara yang besar. Pemerintah memberikan kemudahan-kemudahan untuk TKI, seperti yang melakukan kerja sama antara Kementerian transmigrasi dan tenaga kerja dan juga mendapatkan bantuan sebuah lembaga yang biasa disebut Badan Nasional Penempatan dan Perlindungan Tenaga Kerja Indonesia (BNP2TKI) yang mempunyai fungsi pelaksanaan kebijakan di bidang penempatan dan perlindungan TKI di luar negeri secara terkoordinasi dan terintegrasi.

Fenomena ini tentu menimbulkan keuntungan dan masalah tersendiri bagi pemerintah, dengan adanya tenaga kerja yang bekerja di luar negeri tentu dapat menghasilkan devisa bagi negara, namun tidak sedikit kasus kekerasan yang menimpa tenaga kerja Indonesia di luar negeri. Permasalahan-permasalahan yang terjadi menyangkut pengiriman TKI ke luar negeri terutama tentang ketidaksesuaian antara yang diperjanjikan dengan kenyataan, serta adanya kesewenangan pihak majikan dalam memperkerjakan TKI. Selain itu sering terjadi penangkapan dan penghukuman TKI yang dikarenakan ketidaklengkapan dokumen kerja (TKI ilegal). Dari sisi TKI sendiri, sudah banyak para TKI yang mengalami penganiyaan, pemerkosaan dan tindakan lainnya yang mengakibatkan TKI menerima hukuman fisik, menjadi cacat dan bahkan meninggal dunia. Realita ini menjadi suatu bukti bahwa pemerintah Indonesia masih kurang concern terhadap penanganan masalah TKI di luar negeri. Dibalik keberhasilan perolehan devisa masih terdapat banyak permasalahan yang kompleks, yaitu mulai dari pra penempatan, penempatan TKI baik berdokumen (legal) maupun yang tidak berdokumen (ilegal) dalam penampungan sampai ke negara tujuan, hingga pemulangan kembali ke tempat daerah asal (Mahardika,2014).

Taiwan adalah negara ke-dua setelah Malaysia yang menjadi salah satu negara tujuan CTKI. Total pada tahun 2018 TKI yang berangkat berjumlah 52.629 orang dan 5.932 diwakili oleh penduduk yang berasal dari 
Kabupaten Malang (BPS,2018). Taiwan menjadi salah satu tujuan utama untuk bekerja dikarenakan Taiwan mempunyai standar gaji yang memang lebih tinggi dibanding Hongkong dan Singapura, yakni sebesar Rp. 6.000.000 setiap bulannya, sedangkan standar gaji di Hongkong hanya sebesar 5.000 .000 setiap bulannya (Susilo,2015), tidak hanya itu, Taiwan juga menjadi negara tujuan yang menarik dikarenakan adanya pembebasan visa bekerja (BNP2TKI,2017).

Hal tersebut menjadikan penting untuk meneliti permasalahan yang terbangun di masyarakat terutama dalam bentuk stigma, dikarenakan hal ini tentu menimbulkan sebuah paradigma baru tentang adanya manfaat dan biaya bagi CTKI pada saat pra penempatan, penempatan dan pasca penempatan para CTKI tersebut. Setelah diketahuinya manfaat dan biaya yang akan dihadapi oleh TKI ,tentu yang akan diharapkan adalah kebijakankebijakan dari stakeholder terhadap CTKI yang akan berangkat karena bagaimanapun juga disisi lain TKI adalah salah satu ujung tombak dari perekonomian negara.

Berdasarkan latar belakang yang telah diuraikan diatas maka permasalahan dari penelitian ini adalah 1) Apa saja yang dihadapi oleh TKI dari Taiwan saat pra penempatan, penempatan dan purna penempatan 2) Berapakah biaya manfaat yang akan ditanggung oleh TKI dari Taiwan, sedangkan tujuan dari penelitian ini adalah 1) Peneliti ingin mengetahui apa saja yang dihadapi oleh TKI dari Taiwan saat pra penempatan, penempatan dan purna penempatan 2) Peneliti ingin mengetahui berapakah biaya manfaat yang akan ditanggung oleh TKI dari Taiwan.

\section{METODE PENELITIAN}

Penelitian ini diharapkan memperoleh jawaban dari mantan TKI (purna) yang bekerja minimal 5 tahun di Taiwan dikarenakan negara tersebut adalah negara yang banyak memperkerjakan Tenaga Kerja dari Indonesia yang diharapkan mampu menjadi tolak ukur dari tiap negara tujuan TKI dan akan diambil 15 orang dengan pertimbangan tingkat kesuksesan dari tiaptiap TKI dari yang paling sukses sampai tidak sukses dengan melakukan survey dari kondisi rumah, pekerjaan sekarang maupun tingkat kekayaan dari purna TKI tersebut dan menggunakan metode Non Probability Sample (Selected Sample). Penambahan data deskriptif peneliti juga mecantumkan pejabat Disnakertrans Kabupaten Malang dan salah satu PJTKI sebagai key informan.

Data yang akan digunakan pada penelitian ini dikumpulkan dengan menggunakan metode Non Probability Sample (Selected Sample) dan menggunakan Cost Benefit Analysis yang pengertiannya adalah suatu alat analisis dengan prosedur yang sistematis untuk membandingkan serangkaian biaya dan manfaat yang relevan dengan sebuah aktivitas atau proyek. Tujuan akhir yang ingin dicapai adalah secara akurat membandingkan kedua nilai, manakah yang lebih besar. Selanjutnya dari hasil pembandingan ini, pengambil keputusan dapat mempertimbangkan untuk melanjutkan suatu rencana atau tidak dari sebuah aktivitas, produk atau proyek, atau dalam konteks evaluasi atas sesuatu yang telah berjalan, adalah menentukan keberlanjutannya (Setyagama,2013) 


\section{HASIL ANALISIS DATA}

Hasil dari survey terhadap purna TKI Taiwan dengan metode Non Probability Sample (Selected Sample) didapatkan bahwa hal-hal yang dihadapi oleh TKI dari Taiwan saat pra penempatan, penempatan dan purna penempatan dapat dilihat pada tabel berikut

Tabel 1. Hal-hal yang dihadapi oleh TKI Taiwan

\begin{tabular}{|l|l|l|l|}
\hline No & \multicolumn{1}{|c|}{ Waktu } & \multicolumn{1}{|c|}{ Positif } & \multicolumn{1}{|c|}{ Negatif } \\
\hline 1. & Pra penempatan & $\begin{array}{l}\text { Beberapa PJTKI memberikan } \\
\text { dana tambahan untuk } \\
\text { keberangkatan }\end{array}$ & $\begin{array}{l}\text { Beberapa PJTKI meminta untuk } \\
\text { membayar biaya } \\
\text { pemberangkatan dan potong } \\
\text { gaji }\end{array}$ \\
\hline 2. & Penempatan & $\begin{array}{l}\text { Kontrak kerja mudah } \\
\text { diperpanjang dan standar } \\
\text { upah tinggi }\end{array}$ & $\begin{array}{l}\text { Sikap majikan tempramen dan } \\
\text { kendala bahasa }\end{array}$ \\
\hline 3. & $\begin{array}{l}\text { Purna } \\
\text { penempatan }\end{array}$ & $\begin{array}{l}\text { Standar upah tinggi untuk } \\
\text { modal hidup di negara asal }\end{array}$ & $\begin{array}{l}\text { Purna TKI asal Taiwan lebih } \\
\text { konsumtif }\end{array}$ \\
\hline
\end{tabular}

Sumber : Data Primer Diolah, 2018

Pada tabel 1 dapat dilihat hal-hal yang dihadapi oleh TKI Taiwan saat pra penempatan, penempatan dan purna penempatan dari sudut pandang positif dan negatif, ketika pra penempatan ditemukan temuan yang menarik yaitu faktor PJTKI yang bisa menjadi dua mata koin yang berbeda, hal ini dikarenakan PJTKI ada yang memberikan dana tambahan untuk keberangkatan dan ada juga PJTKI meminta untuk membayar biaya pemberangkatan dan potong gaji. Ketika TKI berada di Taiwan didapatkan bahwa kontrak kerja mudah diperpanjang dan standar upah tinggi namun disisi yang lain TKI cenderung medapatkan sikap majikan tempramen dan permasalahan kendala bahasa, pada saat purna penempatan atau kembali ke Indonesia TKI asal Taiwan mendapatkan modal hidup yang tinggi bila dibanding dengan purna TKI dari negara lain dikarenakan standar upah di Taiwan yang cukup tinggi dan hal ini juga berdampak negatif dikarenakan purna TKI asal Taiwan cenderung bersifat konsumtif hal ini disebabkan gaji yang tinggi ketika bekerja dan fasilitas ketika berada di Taiwan menjadikan suatu kebiasaan baru untuk purna TKI.

Tabel 2. Rata-rata Cost Benefit Analysis Taiwan

\begin{tabular}{|r|c|c|c|}
\hline No & Nama & NPB & BCR \\
\hline 1 & Subiyah & $\mathrm{Rp} 227.140 .656$ & 2,333333333 \\
\hline 2 & Wiwik & $\mathrm{Rp} 220.711 .043$ & 1,625 \\
\hline 3 & Dzulfikar & $\mathrm{Rp} 213.803 .017$ & 1,571428571 \\
\hline 4 & Prayitno & $\mathrm{Rp} 311.992 .370$ & 1,625 \\
\hline 5 & Yuleha & $\mathrm{Rp} 273.500 .000$ & 1,875 \\
\hline 6 & Sri Astuti & $\mathrm{Rp} 341.491 .797$ & 1,857142857 \\
\hline 7 & Riska & $\mathrm{Rp} 615.765 .889$ & 1,6 \\
\hline 8 & Agus & $\mathrm{Rp} 164.009 .157$ & 1,914285714 \\
\hline 9 & Fifi & $\mathrm{Rp} 260.883 .585$ & 1,6 \\
\hline 10 & Abdul Rasyid & $\mathrm{Rp} 324.000 .000$ & 2,142857143 \\
\hline 11 & Jaelan & $\mathrm{Rp} 490.000 .000$ & 1,571428571 \\
\hline
\end{tabular}




\begin{tabular}{|l|c|c|c|}
12 & Bagus Dwi & $\operatorname{Rp} 279.000 .000$ & 1,5 \\
\hline 13 & Khusnul & $\operatorname{Rp~} 148.986 .734$ & 2 \\
\hline 14 & Bambang Sujai & $\operatorname{Rp~} 420.843 .926$ & 1,6 \\
\hline 15 & Sugeng & $\operatorname{Rp} 316.595 .662$ & 2,166666667 \\
\hline & Total & $\operatorname{Rp} 4.608 .723 .836$ & 26,98214286 \\
\hline & Rata-rata & $\operatorname{Rp~} 307.248 .256$ & 1,798809524 \\
\hline
\end{tabular}

Sumber : Data Primer Diolah, 2018

Hasil Cost Benefit Analysis dengan metode Net Present Benefit (NPB) dari tiap Mantan TKI Taiwan menyebutkan bahwa lbu Riska, yang mempunyai NPB tertinggi sedangkan lbu Khusnul mempunyai NPB terendah. Ibu Riska mendapat prioritas tertinggi karena mempunyai manfaat lebih besar dari pada biaya yang diperlukan, dari wawancara yang dilakukan hal itu dikarenakan lbu Riska mempunyai jangka waktu yang relatif cukup lama saat bekerja di Taiwan dan kiriman remittance yang cukup besar, sedangkan lbu Khusnul mempunyai NPB terendah dikarenakan membayar dana awal keberangkatan yang cukup besar dan hanya bekerja beberapa tahun saja. Sedangkan untuk Cost Benefit Analysis dengan Metode Benefit Cost Ratio (BCR). Metode BCR, lbu Subiyah mendapat prioritas teringgi, sedangkan untuk hasil yang terendah adalah Bapak Bagus Dwi hal ini juga tidak lepas dari kurun waktu bekerja dan kiriman remittance. Diluar dari alasan jangka waktu dan kiriman remittance ada beberapa alasan yang mempengaruhi Hasil Cost Benefit Analysis dalam penelitian ini diantaranya adalah potongan-potongan legal maupun ilegal dari PJTKI. Hasil Cost Benefit Analysis mantan TKI Taiwan layak menjadi prioritas karena mempunyai hasil yang signifikan terhadap manfaat yang didapatkan.

\section{PEMBAHASAN}

Ada tiga metode untuk menganalisis manfaat dan biaya untuk uji kelayakan migrasi TKI, yaitu nilai bersih sekarang NPB (Net Present Benefit), IRR (Internal Rate of Return), dan perbandingan manfaat biaya BCR (Benefit Cost Ratio) hasil dari proses perhitungan menjelaskan bahwa metode NPB (Net Present Benefit) lebih signifikan daripada BCR, hal itu dikarenakan Metode BCR mempunyai kelemahan dalam hal membandingkan dua buah proyek karena tidak ada pedoman yang jelas mengenai hal yang masuk sebagai perhitungan biaya atau manfaat. Manfaat selalu dapat dianggap sebagai biaya yang negatif dan sebaliknya. dalam metode NPB terdapat dua macam manfaat-biaya dalam rumus sedangkan dalam BCR sendiri hanya mempunyai satu manfaat-biaya, fungsi dari dua macam manfaat-biaya tersebut dalam penelitian ini adalah ada biaya positif yang dikeluarkan TKI yaitu biaya yang dikirimkan ke Indonesia (remittance) dan manfaat lebih selain gaji yaitu dana awal dari PJTKI, NPB juga mudah digunakan dan fokus pada nilai uang.

Pembahasan diatas secara umum dapat dijelaskan bahwa penyerapan tenaga kerja yang tinggi untuk migrasi ke luar negeri merupakan keuntungan bagi tiap individu dan pemerintah karena hal ini merupakan hal positif yang efisien dalam upaya mengurangi angka 
pengangguran, kemiskinan dan memperluas kesempatan kerja bagi masyarakat dengan tingkat keahlian yang rendah. Selain itu, migrasi ke luar negeri juga merupakan salah satu sumber pendapatan negara yang cukup besar dan efisien, namun demikian, perlu diukur, dihitung dan diuji apakah keuntungan yang diterima oleh tenaga kerja dan pemerintah adalah sebanding, lebih besar atau bahkan lebih kecil daripada kerugian yang harus ditanggung oleh masyarakat dan pemerintah, sebagai dampak dari keberadaan migrasi tenaga kerja ke luar negeri, hal ini tentunya sejalan dengan yang disampaikan oleh Massey (1993), bahwa setiap individu maupun institusi secara rasional melakukan keputusan migrasi dikarenakan analisis manfaat dan biaya yang diharapkan membuahkan hasil yang positif, biasanya secara finansial.

Selain itu terdapat temuan yang menarik dari perhitungan yang dilakukan melalui Cost Benefit Analysis ini, dimana perhitungan dengan metode IRR (Internal Rate of Return) tidak bisa dilakukan, hal ini dikarenakan pada metode IRR kita harus menghitung tingkat suku bunga sendiri untuk dijadikan tingkat bunga impas/standart kelayakan proyek agar bisa direalisasi atau tidak, sedangkan dalam penelitian TKI hal itu tidak bisa dilakukan, karena TKI tidak mempunyai target akan keuntungan yang akan dicapainya, dan Metode IRR dapat menyebabkan pemilihan proyek yang keliru karena metode ini tidak memperhatikan skala investasi, sedangkan untuk penelitian mengenai TKI, investasi bisa berbentuk biaya yang dikirimkan ke Indonesia (remittance).

Keuntungan dari penggunaan analisis manfaat dan biaya dalam menentukan program kelayakan dari migrasi TKI adalah terjaminnya penggunaan sumber ekonomi secara efisien. Program kelayakan dari migrasi TKI yang dianalisis dengan cara ini akan memperhitungkan biaya manfaat secara menyeluruh sehingga dapat meningkatkan penggunaan faktor-faktor yang mempengaruhi biaya manfaat itu sendiri dan dapat tercapai kesejahteraan yang maksimum. Kelemahan dari analisis ini adalah membutuhkan perhitungan biaya manfaat secara kuantitatif, sedangkan program kelayakan dari migrasi TKI tidak dapat diukur secara kuantitatif saja.

Tabel 3. Klasifikasi Manfaat dan Biaya TKI Kabupaten Malang

\begin{tabular}{|c|c|c|c|c|}
\hline & & & Manfaat & Biaya \\
\hline \multirow{4}{*}{ Riil } & \multirow[t]{2}{*}{ Langsung } & Berwujud & $\begin{array}{l}\text { Kiriman } \\
\text { remittance }\end{array}$ & $\begin{array}{l}\text { Pembayaran } \\
\text { PJTKI }\end{array}$ \\
\hline & & $\begin{array}{l}\text { Tidak } \\
\text { Berwujud }\end{array}$ & $\begin{array}{l}\text { Hidup } \\
\text { Diperkaya }\end{array}$ & $\begin{array}{l}\text { Berkurang } \\
\text { waktu dengan } \\
\text { keluarga }\end{array}$ \\
\hline & \multirow[t]{2}{*}{$\begin{array}{l}\text { Tidak } \\
\text { Langsung }\end{array}$} & Berwujud & $\begin{array}{l}\text { Menambah } \\
\text { devisa negara }\end{array}$ & - \\
\hline & & $\begin{array}{c}\text { Tidak } \\
\text { Berwujud }\end{array}$ & $\begin{array}{l}\text { Naiknya status } \\
\text { sosial }\end{array}$ & $\begin{array}{l}\text { Prasangka } \\
\text { buruk } \\
\text { lingkungan }\end{array}$ \\
\hline Semu & & & - & - \\
\hline
\end{tabular}


Tabel diatas menjelaskan tentang klasifikasi manfaat dan biaya dari segi biaya sosial yang terjadi di lingkungan sekitar TKI dari manfaat secara langsung dan tidak langsung,dari biaya langsung dan tidak langsung adapun manfaat semu, akan tetapi tidak ada manfaat semu dalam penelitian mengenai TKI di Kabupaten Malang. Biaya sosial dapat diperkirakan dengan menggunakan prinsip opportunity cost, untuk membedakan dengan biaya untuk pembelian barang bagi individu. Opportunity cost dalam penggunaan sumber daya alam merupakan nilai tertinggi bagi masyarakat dari berbagai alternatif penggunaan sumber daya tersebut. Sehingga pendekatan opportunity cost merupakan pendekatan yang terbaik untuk menentukan nilai dari biaya yang tidak berwujud (intangible value).

\section{SIMPULAN DAN SARAN}

Berdasarkan hasil analisis dan pembahasan yang telah dilakukan dalam penelitian ini, maka kesimpulan dan saran yang dapat disampaikan adalah Kesimpulan dari hal-hal yang dihadapi oleh TKI Taiwan saat pra penempatan, penempatan dan purna penempatan adalah ketika pra penempatan PJTKI ada yang memberikan dana tambahan untuk keberangkatan dan ada juga PJTKI meminta untuk membayar biaya pemberangkatan dan potong gaji. Ketika TKI berada di Taiwan didapatkan bahwa kontrak kerja mudah diperpanjang dan standar upah tinggi namun disisi yang lain TKI cenderung medapatkan sikap majikan tempramen dan permasalahan kendala bahasa, pada saat purna penempatan atau kembali ke Indonesia TKI asal Taiwan mendapatkan modal hidup yang tinggi bila dibanding dengan purna TKI dari negara lain dikarenakan standar upah di Taiwan yang cukup tinggi dan hal ini juga berdampak negatif dikarenakan purna TKI asal Taiwan cenderung bersifat konsumtif hal ini disebabkan gaji yang tinggi ketika bekerja dan fasilitas ketika berada di Taiwan menjadikan suatu kebiasaan baru untuk purna TKI.

Hasil perhitungan Cost Benefit Analysis dari 15 mantan TKI secara keseluruhan memenuhi syarat untuk diprioritaskan, karena dalam metode Net Present Benefit (NPB) maupun dengan Metode Benefit Cost Ratio (BCR) semuanya menunjukan bahwa hasil perhitungan yang layak untuk dijalankan. Hasil Cost Benefit Analysis dengan metode Net Present Benefit (NPB) dari tiap Mantan TKI Taiwan menyebutkan bahwa lbu Riska, yang mempunyai NPB tertinggi sedangkan lbu Khusnul mempunyai NPB terendah. Ibu Riska mendapat prioritas tertinggi karena mempunyai manfaat lebih besar dari pada biaya yang diperlukan, sedangkan lbu Khusnul mempunyai NPB terendah dikarenakan membayar dana awal keberangkatan yang cukup besar dan hanya bekerja beberapa tahun saja. Sedangkan untuk Cost Benefit Analysis dengan Metode Benefit Cost Ratio (BCR). Metode BCR, lbu Subiyah mendapat prioritas teringgi, sedangkan untuk hasil yng terendah adalah Bapak Bagus Dwi hal ini juga tidak lepas dari kurun waktu bekerja dan kiriman remittance.

Diluar dari alasan jangka waktu dan kiriman remittance ada beberapa alasan yang mempengaruhi Hasil Cost Benefit Analysis dalam penelitian ini diantaranya adalah potongan-potongan legal maupun ilegal dari PJTKI. 
hasil dari wawancara mendapatkan cukup banyak TKI yang terlibat masalah, dari saat pemberangkatan dengan modal yang kurang, PJTKI yang bermasalah ataupun yang memotong gaji terlalu besar, saat berada di negara tujuan mendapatkan majikan atau tempat bekerja yang kurang kondusif dan saat kembali ke Indonesia dengan sedikit uang atau penipuan berkedok travel, akan tetapi ada juga yang sukses mendapatkan gaji dan uang remittance yang memadai.

\section{DAFTAR PUSTAKA}

BNP2TKI, 2017. Data Statistik Tenaga Kerja Indonesia Menurut Pengganguran Terbuka 2012-2017. Jakarta: BNP2TKI-Indonesia.

BNP2TKI, 2015. Crisis Center BNP2TKI Tangani 12270 Pengaduan Permasalahan TKI - Jakarta, BNP2TKIGOID.

Badan Pusat Statistik Jakarta Pusat, 2018. Statistik Indonesia Tahun 2018. Jawa Timur : Badan Pusat Statistik.

Dinas Tenaga Kerja Transmigrasi dan Kependudukan, Indonesia.2017. Lembaran Informasi Ketenagakerjaan.Tahun 2017.

Kuswadi, 2005. Cara Mengukur Kepuasan Karyawan. Cetakan Kedua, Jakarta

Kusumastanto, Tridoyo, 2000. Valuasi Ekonomi dan Analisis Manfaat Biaya Pemanfaatan Sumberdaya Pulau-Pulau Kecil. Lokakarya Pendekatan Penataan Ruang dalam Menunjang Pengembangan Wilayah Pesisir, Pantai dan Pulau-Pulau Kecil.Ditjen P3K Departemen Kelautan dan Perikanan di Jakarta, 10 Oktober 2000.

Mahardika, Alam. dkk. 2014. Perekrutan dan Penempatan Tenaga Kerja Indonesia (TKI) oleh Dinas Tenaga Kerja dan Ttansmigrasi DKI Jakarta. Fakultas IImu Sosial. Universitas Negeri Yogyakarta.

Masey, et al.,1993. Theories of International Migration; An Integration and Appraisal,in Population and Development Review, Vol.19(3) 431-66.

Michael P. Todaro, 2000, Economi Development, Seventh Edition, New York University, Addison Mesley.

Raharto, Aswatini. 2017. Pengambilan Keputusan Tenaga Kerja Indonesia (TKI) Perempuan untuk Bekerja di Luar Negeril: Kasus Kabupaten Cilacap. Jurnal Kependudukan Indonesia. Vol. 12 No. 1 Juni 2017 ( 39-54). Pusat Penelitian Kependudukan - LIPI.

Setyagama, Anggra Sukma. 2013. COST AND BENEFIT ANALYSIS (CBA). http://anggraica.blogspot.com/2013/06/cost-and-benefitanalysis-cba.html (diakses 18 Oktober 2018).

Undang undang No 39 Tahun 2004 : Tentang Penempatan dan Perlindungan Tenaga Kerja Indonesia di Luar Negeri.Kementrian Tenaga Kerja dan Transmigrasi Republik Indonesia. 